\title{
Forgotten but Not Gone
}

\author{
The Impact of the Opioid Epidemic and Other \\ Substance Use Disorders on Families and Children
}

DENNIS C. DALEY

University of Pittsburgh Medical Center, University of Pittsburgh

School of Medicine, Department of Psychiatry

ERIN SMITH

British Columbia Children's Hospital, British Columbia Women's Hospital

DANIEL BALOGH University of Pittsburgh Medical Center

JODI TOSCOLANI

University of Pittsburgh Medical Center

This article discusses the impact of the opioid epidemic and other substance use disorders (SUDs) on families and their members, including children. We review factors contributing to this major public health and safety problem, current trends in opioid and other substance use and misuse, prevalence of opioid use disorders (OUDs) and other SUDs, and interventions to help families. Sources of information for this article include research, clinical and recovery literature, government reports, experiences of the two senior authors in clinical settings, and interviews and surveys of family members affected by a loved one's SUD.

\section{The Opioid Epidemic and Other Substance Use Disorders}

merica is in the throes of an opioid epidemic as a result of the rapid rise in individuals who misuse opioids or develop an opioid use disorder (OUD) and become addicted to prescription opioids used to 
treat pain, or to illicit opioids like heroin or fentanyl (ACAP 2017; Cicero, Ellis, and Suratt 2015; Frank and Pollack 2017; Koh 2015; Schuckit 2016). This epidemic has led to a substantial increase in the number of overdose deaths from opioids and other drugs and a five-fold increase in babies of opioidaddicted mothers born with Neonatal Abstinence Syndrome (Alexander 2015; Dart et al. 2015; Jansson and Velez 2010; Jones et al. 2010; SAMHSA 2016). In addition to OUDs, other substance misuse and SUDs have an impact on individuals and families and contribute to or exacerbate medical, psychiatric, family, social, and legal problems (Berry et al. 2013; Compton 2015; Daley and Douaihy 2017; Douaihy and Daley 2013, 2017; Friedman 2013; Kendler et al. 2016; Schuckit 2016; Soyka 2017; Volkow et al. 2014). These problems present challenges to medical, social service, and criminal justice systems, and highlight the need for services and interventions to help families affected by SUDs.

Media attention and national dialogue on the opioid epidemic has increased in recent years. The focus, however, has primarily been on overdose statistics, causes, and political discourse about the best course of action for this problem. While many reports and papers detail interventions to help individuals with SUDs, limited attention is given to the support that families and children need to help them cope with a loved one's SUD and the impact it has on their lives.

\section{Current Trends in Opioid and Other Substance Use, Misuse, and SUDs}

A recent National Survey on Drug Use and Health published by the Substance Abuse and Mental Health Services Administration (SAMHSA 2016) shows that over 119 million people ages 12 or older used prescription drugs with addiction potential during 2015 (see Figure 1), and nearly 19 million misused these drugs.

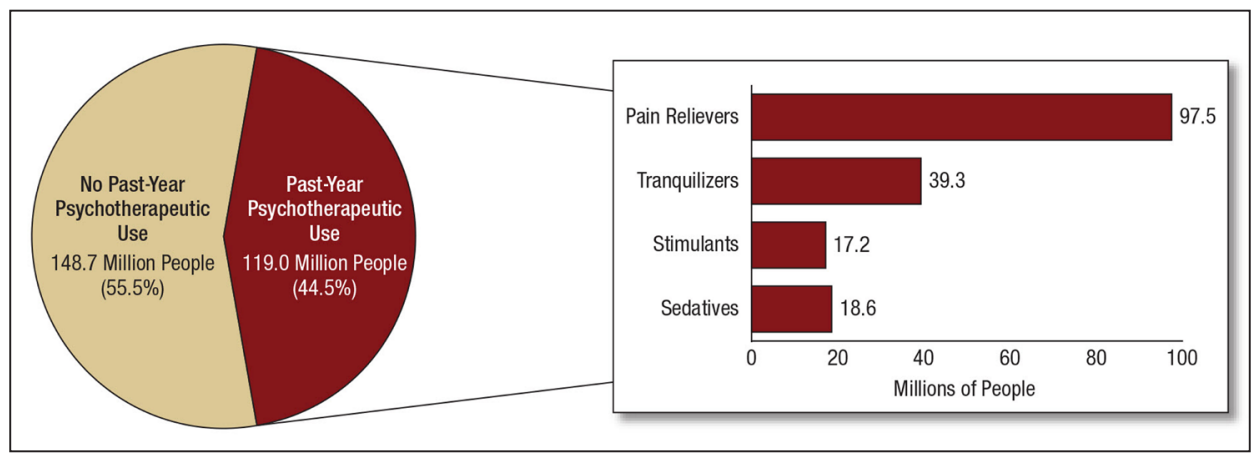

Figure 1. Numbers of Past-Year Prescription Psychotherapeutic Drug Users Among People Aged 12 or Older in 2015. (SAMHSA, National Survey on Drug Use and Health, Substance Abuse and Mental Health Services Administration 2016.) 
Many users get these drugs from family, friends, or dealers and not from a physician. This SAMHSA survey also found that in the past month over 27 million used illicit drugs (see Figure 2), and over 64 million used tobacco products. The latter contributes to nearly 500,000 deaths per year as mortality rates are three times higher among smokers compared to nonsmokers (CDC 2017).

This SAMHSA survey also found (see Figure 3) high rates of alcohol use, binge drinking (four or more drinks per occasion for a woman, or five or more for a man) or heavy drinking (multiple binge episodes). Even a single episode of binge or heavy drinking can lead to a serious or fatal accident or injury.

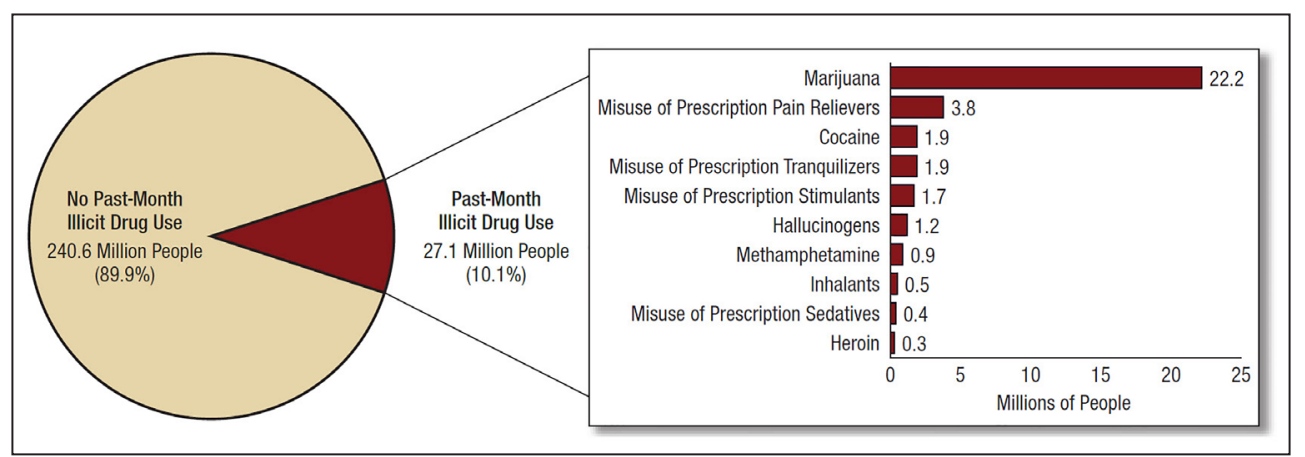

Figure 2. Numbers of Past-Month Illicit Drug Users Among People Aged 12 or Older in 2015. (SAMHSA, National Survey on Drug Use and Health, Substance Abuse and Mental Health Services Administration 2016.)

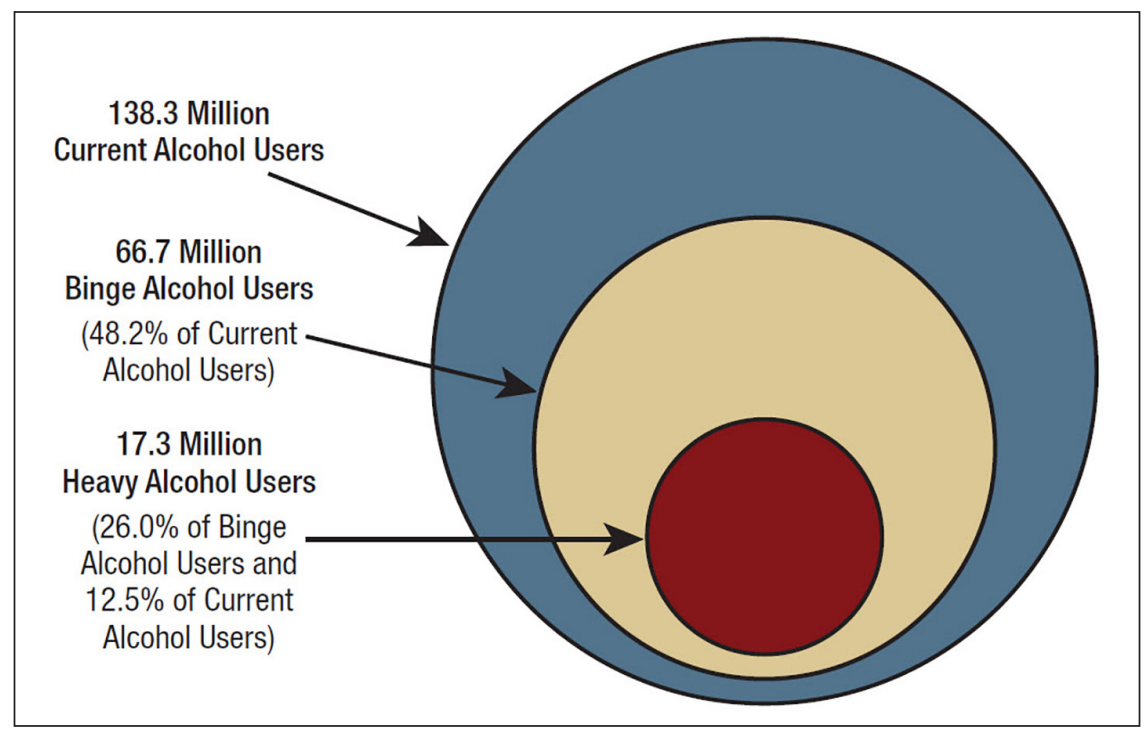

Figure 3. Number of Alcohol Users, Binge Drinkers, and Heavy Drinkers. (SAMHSA, National Survey on Drug Use and Health, Substance Abuse and Mental Health Services Administration 2016.) 
Findings from the National Epidemiologic Survey on Alcohol and Related Conditions found increases in alcohol use, high-risk drinking, and alcohol use disorders (AUDs) from 2001 through 2013. Alcohol use increased among the total adult population from $65.4 \%$ to $72.7 \%$, high-risk drinking increased from $9.7 \%$ to $12.6 \%$ of the population, and alcohol use disorders increased from $8.5 \%$ to $12.7 \%$ of the population (Grant et al. 2017). Most alarming was the significant increase among women whose drinking behavior rose by $57.9 \%$ for heavy drinking and by $83.7 \%$ for AUDs.

The SAMHSA study also found that nearly 21 million or $7.8 \%$ of the population had a substance use disorder (SUD) in the past year. This includes 15.7 million with an alcohol use disorder, 7.7 million with an illicit drug use disorder, 4 million with a cannabis use disorder, 2.6 million with a prescription or illegal opioid use disorder, and over 2 million with a stimulant use disorder (cocaine, methamphetamine, prescription stimulants). These are rates of SUDs among individuals in the community. Rates of these disorders in medical, psychiatric, addiction, and criminal justice systems are much higher. Numerous individuals have more than one type of SUD. In addition, epidemiologic and clinical studies show that many individuals with an SUD also have a coexisting psychiatric disorder (Daley and Thase 2004; Kelly and Daley 2013; Kessler et al. 1997; SAMHSA 2016; Regier 1990).

An unfortunate reality is that the large majority of those with an SUD never receive treatment. The SAMHSA study found that only $11.5 \%$ of individuals with an SUD received treatment and less than 2\% with an SUD thought they needed it (SAMHSA 2015a). A report by Columbia University found similar low rates of engagement in services for SUDs with nearly half of referrals coming from the Criminal Justice System (CASA 2012). This speaks to the importance of the legal system intervening to engage more individuals with an SUD in treatment, and to divert individuals from incarceration to treatment when appropriate. In fact, if it were not for legal pressure to get help, many with an SUD would deteriorate even more, and families would experience more frustration and worry. Individuals with SUDs who received help for their problem while in jail or prison had better outcomes compared to those who did not receive this help (Freudenberg and Heller 2016).

\section{Current Trends in Treatment of SUDs Affecting the Family}

As expected, families are concerned with the low rates of treatment entry as well as the barriers and limitations of treatment systems, such as lack of quick and easy access to treatment when their loved one agrees to get help for the SUD, barriers to medication-assisted treatment (MAT) for opioid addiction, 
limited professional care to support long-term recovery after a rehabilitation program, limits to funding to pay for certain types of treatment, and limited or lack of services for families when their loved one is in treatment or refuses treatment. Rural areas often lack adequate treatment services, which presents another barrier to treatment (Van Gundy 2006).

Factors contributing to the low rate of treatment utilization include lack of awareness of the SUD by the affected person, minimizing the severity of the SUD and need for treatment, low level of motivation to accept help, and being controlled by addictive drugs. Once an individual is addicted to an opioid drug and uses regularly, the brain's reward center becomes hijacked. Repeated use of the drug is associated with environmental stimuli or "cues" that can trigger strong cravings even after a period of being drug free. Drug use becomes more reinforcing than ordinary healthy rewards associated with food, sex, relationships, accomplishments, or other positive experiences in life (Volkow and Fowler 2000; Volkow, Koob, and McLellan 2016).

In addition, executive processes in the prefrontal area of the brain may become seriously impaired so that the individual becomes less able to control desires to use and is more prone to making unhealthy or impulsive decisions.

Understanding some of the basic neurobiology of addiction may help families become more understanding, patient, and tolerant of the member who struggles with initiating or sustaining recovery following an episode of treatment. An important point for families to understand is that even addicted people who are motivated to change can be overwhelmed with the intensity of a drug craving triggered by positive memories or environmental cues (specific people, places, or objects such as needles, drug paraphernalia, pipes, pills, liquor bottles). This may also help some families understand the importance of medication-assisted treatment (MAT) for addiction to opioids or alcohol to reduce the intensity of opioid or alcohol cravings. When cravings are controlled, the person with the SUD is more able to use coping skills to manage the other challenges of recovery.

Individuals with SUDs are more likely to enter treatment as a result of a mandate or pressure from the legal system, an employer, or the family. It is common for these individuals to have external motivation initially. As a result of the opioid epidemic, more individuals with an OUD are now receiving professional help, although rates of treatment entry are still too low. Most resources to pay for treatment cover the "acute phase" of care in a residential rehabilitation, partial hospital, or intensive outpatient program rather than "long-term" care in outpatient settings.

Some families have been encouraged by the recent increase in the use of MATs for OUDs, which are associated with positive outcomes (Baser, Chalk, Fiellin, and Gastfriend 2011; Baser, Chalk, Rawson, and Gastfriend 
2011; McCarty et al. 2010). More medical providers are now offering MAT to patients with OUDs in primary care practices, hospitals, or other medical or psychiatric practices (Liebschutz, Crooks, and Herman 2014; Stine and Kosten 2014; Weiss et al. 2015). All states have approved naloxone access laws in recent years. This has resulted in more drug overdoses being reversed by first responders, other drug users, and family members. This provides some relief to families who worry about the possibility of death from an overdose for their loved one. Our family survey found that families' greatest fear was the possible death of their loved one from overdose (Ward and Daley 2014).

\section{Factors that Mediate the Impact of SUDs on the Family}

Not all families or members within a family are affected in the same way by a member's SUD. However, these disorders often create ripple effects through the family. Countless lives are irrevocably altered in the "collateral damage" caused by an SUD. The burden of living with an SUD falls far beyond a single person. Commonly, many affected families suffer in silence, ashamed and unsupported, with limited access to services that address their needs. The effects can be felt even years after living with a family member who has an SUD (Ackerman 1987, 2002).

\section{Severity of the SUD}

Factors that mediate the impact of SUDs on families and individual members include substances used (amount, type, frequency of substance use), methods of administration, severity and duration of the member's SUD, behaviors of this individual, and whether a co-occurring mental health or medical disorder is present (Daley and Miller 2001). For example, a family with an unemployed parent who has a severe drug addiction requiring daily multiple injections of heroin will experience different worries and stressors than a family who has a member with a moderate alcohol use disorder who is able to work. A family exposed to chronic alcohol dependence, with erratic behavior including violence during periods of intoxication, will be affected differently than a family whose member is addicted to prescription sedatives but does not evidence poor self-control or violent behaviors toward family members.

\section{Loss of a Family Member}

SUDs can lead to loss by separation, divorce, incarceration, death, or loss of role functioning as a parent. Parents and spouses can attest that losing a loved 
one to a drug overdose or accident caused by alcohol intoxication elicits a different reaction than death from cancer. One mother found her 20-year-old daughter unresponsive due to a drug overdose "in the same room where we had tea parties, bedtime stories, slumber parties, and mother-daughter nights with snapchats and long talks" (Schwartzmier 2017). This overdose occurred a day before this young woman was to enter a rehab program for her addiction. A couple lost their son after he got drunk and died as a result of a head trauma from falling 30 feet and hitting his head on a hard surface (Gaines 2011).

Some families who do not have a member with an SUD lose a loved one as a result of accidents caused by intoxication of a stranger, or gun violence. Families have lost loved ones as a result of drunk/drugged driving accidents or accidental shooting. One woman lost her mother and young daughter at the same time when they were struck by a drunk driver. Another lost a teenage son to random violence associated with a conflict over drugs. While data and study results can identify the prevalence of problems and specific effects on individuals, no data can convey the extent of the emotional pain and heartache experienced by family members who lose a loved one as a result of a drug overdose, accident, medical complication, or murder.

\section{Impact on Health}

Intense and persistent emotions caused by the loss of a loved one to an addiction can affect the physical and mental health of family members. A range of emotions is experienced as the family member tries to understand and make sense of what happened, and why it happened (White 2014). One mother stated, "I was sad, angry, in denial, depressed, crazy, panic stricken, any or all of these feelings in one day, sometimes in one hour, one minute" (Daley 2017a). Many had difficulty sleeping, lost their appetite, had to force themselves to get out of bed, and had to push themselves to take care of other children or go to work. Some felt so despondent that they wished they would die. Those parents who have lost a child to overdose are more likely to succumb to grief, depression, post-traumatic-stress disorder, or other mental health problems compared to those who have lost a child to accidents or natural death (Yule, Wilens, and Rauch 2017). Family members whose loved one is in treatment may worry about the possibility of relapse, particularly if this member has a history of multiple treatment episodes followed by relapse. Some family members experience adverse effects even years after exposure to an SUD, regardless of whether their loved one established sobriety. 


\section{The Impact of Substance Use Disorders on the Family and Members}

It is estimated that $20 \%$ or more of the population has a family member with an SUD (Liepman et al. 2014; Minear and Zuckerman 2013; Smith and Daley 2017), which means that these disorders have an impact on a large number of families. Many studies and reports have documented negative effects on family, marital, financial, and emotional stability; on parental competence; on how the family functions within and outside of the family; and on the physical and mental health of individual members (Lander, Howsare, and Byrne 2013; Ward and Daley 2014; Weisner 2010; White and Savage 2005; Young et al. 2015).

Family cohesion and communication are affected, and it is common for the SUD to be a major focus of the family. Parenting behaviors are affected. Fathers with an SUD may be absent or unable to provide nurturing to children that is needed for healthy child development (McMahon 2013).

Physical, sexual, or emotional abuse may occur as a result of intoxication or poor judgment associated with an SUD. Behavior such as threatening family members, lying, manipulation, failed promises, and using family income for drugs harms the family and creates insecurity (White and Daley 2016). The individual with an SUD may have no memory of exhibiting violent or hurtful behavior or may deny that this occurred, which can confuse or damage the victim. Divorce or separation due to marital strife, incarceration, and repeated admissions to hospitals or rehabilitation centers can also occur and upset the stability of the family. An SUD may have lead to a disruption of family roles, such as grandparents raising grandchildren, or teenagers caring for younger siblings.

It is common for families to experience the loss of a loved one during the active phase of an SUD because the affected member is controlled by substances, and often does not function as a responsible parent or family member. This can have an impact on family stability, cohesion, and communication. Communication breakdown can lead to secrecy, confusion, embarrassment, and chaos in the family.

Family members may feel helpless, hopeless, cheated, ashamed, worried, angry, depressed, anxious, and demoralized (Liepman et al. 2014; Wallace 2014). The emotional burden can be quite high, and some family members need professional help for clinical depression or an anxiety disorder. Anger, frustration, and a profound sense of helplessness contribute to conflict and division between spouses, among siblings, and in the parent-child relationship. Some family members feel so upset that they cut ties with the member 
who has the SUD. In a quality improvement study of outpatients conducted by one of the senior authors, $91 \%$ of patients reported that they created an emotional burden on their family causing anger, fear, and mistrust (Daley and Moss 2002).

Families lose the feeling of safety if the member with the SUD is violent, suicidal, or unpredictable. Trust can be lost when a parent does not function as a responsible adult. Children may not get the consistency, love, nurturing, or mentoring needed to help them cope with life (Daley and Tarter 2017; McMahon 2013). Or, they may be removed from the home as a result of problems caused by parental substance use. Rates of removal from the home in families with a member with an SUD from 2000 (18.5\%) through 2015 (34.4\%) have almost doubled (Daley 2017b). In the quality improvement study mentioned previously, $37 \%$ of patients with children reported that they either had relatives take care of their children or had them removed by child welfare (Daley and Moss 2002).

Families who experience poverty or a financial burden may feel insecure or fall into debt due to unemployment, underemployment, misuse of family financial resources, or paying for legal or treatment fees that the family can hardly afford. Some parents borrow large sums of money, take out second mortgages, or withdraw money from retirement accounts to pay for treatment for the affected member.

Another type of loss occurs when a parent or other family member with the SUD is incarcerated. SUDs contribute to a broad range of behaviors leading to involvement in the Criminal Justice System (Freudenberg and Heller 2016). A parent or other family member sent to prison creates stresses for the family. A mother that one of the authors worked with lost her addicted son when he went to prison for manslaughter following an incident in which he shot and killed another man while fighting over a drug debt. Her son going to prison was a significant factor in a worsening of her clinical depression.

Losing an adolescent or young adult child shatters the parent's, grandparent's, and sibling's worlds, and changes their perspective. This can affect their emotional stability, relationships, and how they function. A parent may feel guilty and wonder if he or she could have done anything differently to prevent the death of their child. Losing a sibling is painful for brothers or sisters left behind.

While most of this discussion is on the impact of SUDs on the family, members are also affected by the impact of treatment and recovery, both in positive and negative ways. Initially, families often feel relieved when their loved one enters treatment, especially if they are provided an opportunity to share their experiences, express their concerns, and learn coping strategies. Families 
develop hope for positive change as they learn about effective treatments and the potential positive impact on their affected member and their family unit.

However, families not invited to participate in treatment may feel resentful and feel left behind as the member with the SUD receives help and attention from professionals and others in recovery. While the behavior associated with an SUD during active addiction often upsets the family, so can behavior during recovery. Some family members, for example, complained that their loved one was absent during the active phase of addiction as well as during recovery as a result of attending meetings and focusing most of their efforts on recovery from addiction. While it is critical for the member with the SUD to prioritize recovery, this must be done in a way that the family is not excluded, forgotten, or ignored. In addition, roles in the family can change as a result of recovery, as in the case of a father becoming more active in raising children after limited involvement during his addiction. The nonaddicted spouse may find it hard to adapt to sharing the power of parenthood. This is just one example of how family dynamics can be affected by a positive event such as a member with an SUD engaging in treatment and recovery.

\section{Positive Coping and Resilience of Family Members}

Individuals and families affected by addiction are some of society's most resilient members. Family members may bond more closely together. Some use their experiences for motivation to work hard and be successful. Others use their experiences to educate, support, or help others affected by an SUD (see resource section later in this article for examples of organizations in which family members in recovery play a significant role in helping others). Protective factors that help offset some of the negative effects of an SUD on members include the use of positive psychological coping mechanisms, social skills, and positive connections with parents, other relatives, teachers, or other adults (Ackerman 1987; Daley and Miller 2001).

\section{The Effects of Substance Use Disorders on Children}

Children are affected by SUDs, yet receive little mention in the national dialogue and policy (Orford et al. 2013; White and Daley 2016). Denniston reviewed the 2016 Surgeon General's Report on Alcohol, Drugs and Health and stated that while this report is comprehensive and informative in many ways, it "neglected to include children of addiction" (Denniston 2017, 10). One of the authors of this article (DD) reviewed the indexes of the three major textbooks on addiction and the titles of 136 studies funded by the National Institute on Alcohol Abuse and Alcoholism (NIAAA) and 448 studies funded by the 
National Institute on Drug Abuse (NIDA) and found that only $4 \%$ of the total pages in the textbooks focused on issues related to families or children, and only about $2 \%$ of the studies included anything about the family or children in the titles of the research grants.

The impact of SUDs on children is variable, but the increased risk for a range of problems is well documented. Adverse effects are greater when both parents have an SUD, as these disorders impede parenting and the ability to provide a nurturing environment for children (Barnard and McKeganey 2004; Conners et al. 2004; Solis et al. 2012). Multiple studies and reports show that children of parents with SUDs are at increased risk for: abuse or neglect, leading to involvement in the child welfare system; physical health problems; social skill deficits; emotional or psychiatric problems such as anxiety, depression, or low self-esteem; behavioral problems such as oppositional behaviors; and academic problems such as lower grade point averages, increased grade retention, or failure to pursue secondary education (Andreas-Burdzovic and O’Farell 2007; Barnard and McKegany 2004; Daley 2017b; Kirisci, Vanyukov, and Tarter 2005; Solis et al. 2012; Salo and Flykt 2013; Moss et al. 1995; Smith and Daley 2017; Tartar et al. 1995; 2004; Young et al. 2015).

Nunes conducted two pivotal studies collecting data about the children of opioid-addicted patients who were enrolled in a methadone clinic (Nunes et al. 2000). This implied current stability in their addiction, yet also suggested a chronic and severe course in order to qualify for treatment with methadone. One study analyzed information from evaluations of 283 children, ages 6-17, from diverse ethnic backgrounds. Results showed that this age group was an at-risk population for psychiatric problems including mood disorders (20\%), anxiety disorders (24\%), behavioral disorders (30\%), academic problems (37\%), and general global impairment in their day-to-day functioning (25\%). Nunes' studies replicated the findings of earlier studies of children whose parents had opioid, cocaine, or alcohol use disorders that showed that children were at increased risk for a variety of problems.

SUDs interfere with providing a consistent environment for children that is crucial for normal child development (Suchman, Pajalo, and Mayes 2013). A mother's addiction can lead to attachment problems in the child as a result of the mother being less attentive and engaged during interactions with her infant (Salo and Flykt 2013). This can lead to problems during childhood and influence adult relationships later in life.

SUDs among pregnant mothers are associated with medical complications during pregnancy and delivery including premature birth, fetal alcohol syndrome disorders, or neonatal abstinence syndrome among babies born to women addicted to opioid drugs (Committee on Obstetric Practice 2017; 
Jansson and Velez 2010; Kraft et al. 2017; NIAAA 2017; Viteri et al. 2015). Children born to addicted mothers are also at increased risk for developmental and psychological problems. While most of the research has been on babies born to mothers with opioid or alcohol dependence, cigarette smoking and other drug use including marijuana, cocaine, and methamphetamine can contribute to a miscarriage or have an adverse effect on fetal growth, birth weight, asthma, and sudden infant death syndrome (Suchman, Pajalo, and Mayes 2013).

\section{Help for Families and Children}

Families benefit from professional guidance in addressing the SUD (Copello, Velleman, and Templeton 2005; Kaufman and Yoshioka 2004; Liepman et al. 2014). Families can facilitate their affected member's involvement in treatment; attend sessions together to address the SUD and recovery needs; engage in discussions about addiction, treatment, and recovery, the impact on the member and family unit, and what can and cannot be done to help the member with the SUD; point out early warning signs of relapse that their loved one may ignore; and help them stabilize from a relapse should one occur.

Families can help themselves by discussing their experiences with the member with the SUD, examining and changing their own behaviors and emotional reactions, and examining ways to make changes within the family system. Any of these changes can be accomplished by involvement in treatment and/or mutual support programs. While family members often enter treatment and/or mutual support programs initially to help their loved one, they often discover that they need emotional support and help to deal with the impact of the SUD on their behaviors and emotional health.

Professional interventions usually fall into one of three categories: (1) those oriented toward helping the family influence the member with the SUD to enter treatment; (2) those in which family members engage in treatment with the member who has the SUD in education groups, multifamily groups, individual family, or couples therapy sessions; and (3) those that help family members address their own concerns, problems, and emotions without the member with the SUD engaging in these sessions (Templeton, Velleman, and Russell 2010). In addition, there are limited services available to help children affected by SUD in their family.

\section{Interventions to Help Family Members Engage Their Loved One in Treatment}

The initial push to engage family members with SUDs in treatment is often a result of intervention by the legal system, employers, or their families. Family 
and couples or marital approaches significantly improve treatment engagement and retention rates (Klosterman and O'Farrell 2013; Landau et al. 2000; SAMHSA 2009; Szapocznik et al. 2013). Several approaches focus mainly on helping the family or social network develop strategies to influence their loved one with an SUD to engage in treatment. These strategies include "joining" the family, eliciting family strengths, reviewing previously attempted engagement strategies, determining alliances within the family, and identifying options to influence and engage the member with the SUD in treatment.

Family treatments may also focus on communication and encourage families to change the way they interact with their loved one as a strategy to influence treatment engagement. Research shows that these family approaches lead to significantly higher treatment engagement rates compared to treatment as usual, with $64 \%-93 \%$ of members with an SUD engaging in treatment compared to $25 \%$ who receive usual care and not the specialized intervention (Landau et al. 2000; Szapocznik, Hervis, and Schwartz 2003).

\section{Interventions for Couples and Families}

There are multiple family and couples approaches to treatment. Some focus mainly on families with an adolescent member, while others focus on families in which an adult member has the SUD.

Family sessions may focus on strategies to stop or reduce substance use and identify adverse consequences of substance use on the individual and family. Other strategies may focus on how to improve motivation to change; family communication and parental behaviors; how to reduce conflict; ways to increase positive reinforcement by rewarding behavior changes; how to stop violence; or how to identify and manage triggers for relapse. Family sessions may also focus on problems specific to a given family.

In addition, approaches for adolescents may focus on improving parentadolescent interactions, improving school attendance and academic performance, and reducing behavioral or delinquency problems or high-risk sexual behaviors (NIDA 2012; Szapocznik, Hervis, and Schwartz 2003). Results of multiple studies show that these approaches lead to improvements for the member with the SUD and for other family members (NIDA 2012; Klosterman and O'Farrell 2013; Meyers and Wolfe 2004; Stanton and Shadish 1997).

Treatment provided to spouses and partners is effective in helping the member with the SUD achieve abstinence or reduce substance use or relapses after a period of sobriety. Couple-based therapy improves the relationship and supports recovery for both partners. Developing a "recovery contract" is a central component, with "daily rituals" that the couple engages in to reward 
continued abstinence. Therapy emphasizes communication and reintroduction of positive experiences, which are often lost when one partner is in active addiction (Klosterman and O'Farrell 2013).

A key part of any discussion with families must include knowledge that effective treatments for OUDs and other SUDs exist and that people do get better; many who respond to treatment go on to lead productive and fulfilling lives. Another key understanding for families is that there are no short-term answers or treatments for SUDs. Although their loved one may prefer limited involvement in treatment, long-term involvement is usually needed to sustain changes and reduce relapse risk.

With OUDs, families need to learn that MATs with methadone or buprenorphine are effective treatments, and that they are used in combination with addiction counseling (Kmiec, Cornelius, and Douaihy 2013; Stine and Kosten 2014). Families sometimes are resistant to the idea of a loved one using another drug to replace heroin or an addictive prescription drug. However, recovery rates are superior when a person with an OUD receives MAT. Medications can also aid recovery from alcohol dependence, so families should gain an understanding of this MAT (Myrick et al. 2014; SAMHSA 2015b).

Addiction is often described as a chronic relapsing and remitting disease, and families sometimes feel hopeless and helpless when their loved one relapses. Helping to prepare individuals and their families for the reality of a relapse is a key part of recovery. Families may become more realistic and feel more hopeful when they learn that relapses are common, that they can influence the member with the SUD to change their treatment plan if a relapse occurs, and that an actual relapse can be stopped and the damage minimized if the member with the SUD or the family takes quick action (Daley and Douaihy 2015; Marlatt and Donovan 2005).

Given the significant increase in drug overdoses, families benefit from learning how to use naloxone to reverse overdose and how to participate in drug take-back programs, in which unused opioid medications can be removed from the home to reduce future misuse. Access to the drug naloxone at home may help reduce the fear that families often have about losing a loved one from a drug overdose. In a study conducted by the Massachusetts Department of Public Health, members who received both overdose education and a naloxone rescue kit felt that they could respond to an overdose and save the life of a loved one if needed (Bagley et al. 2017).

\section{Interventions for Individual Family Members}

Some family approaches help members improve their coping skills and enrich their lives as they become more confident and able to deal with their loved 
one's SUD and change their own behaviors and emotional reactions. Even if the family member with the SUD refuses help and does not engage in treatment, other family members still can benefit from treatment. Family members can make positive changes and decrease undesirable behaviors that are not helpful to the person with the SUD, such as not arguing, nagging, or confronting this person in a hostile manner (Meyers and Wolfe 2004). Parents can increase their parental competencies and skills (Daley 2017b).

In some instances, family members may need help for their own substance use, a mental health problem, or other problem. Some family approaches offer individual sessions for these family members. In other instances, family members benefit from a referral to a psychiatrist, psychologist, or counselor, depending on the nature of their current problems. Similarly, children who have substance use, mental health, academic, or behavioral problems may benefit from a mental health evaluation and treatment provided in the school system or community.

\section{Mutual Support Programs for Families}

Another helpful intervention, which may be used independently of treatment or may result from the encouragement of a professional, is engaging in a mutual support program (MSP) such as Al-Anon, Nar-Anon, or Alateen (Al-Anon Family Groups 1981, 1984). While these programs are available throughout the United States, some family MSPs are specific to local communities.

MSPs can help families become educated about SUDs and the impact they have on the affected person, the family system, and individual family members. They receive support and guidance from others who have learned to cope with addiction in their families. They learn about recovery and how to take steps to manage their own lives and to become less obsessed with the member who has the SUD.

Family members who embrace the program espoused by MSPs and engage in their own recovery may make changes that enhance their health and wellbeing such as the following:

- Accept that they cannot make the member with the SUD change

- Reduce their preoccupation with the member with the SUD so this is not the central focus of their lives

- Stop unhelpful behaviors such as covering up, or bailing the member with the SUD out of trouble

- Talk about their own behaviors and emotions with other adults to get help and support, and learn from their experiences 
- Move toward forgiveness of the member with the SUD

- Decrease self-blame for the problem

- Build on their strengths

- Focus more attention and energy on nonaddicted family members

- Keep up friendships and stay active in family, community, or religious activities

- Other changes that may be unique to a specific person (Daley and Douaihy 2010)

Some family members "give back" by mentoring or sponsoring other family members new in recovery. Others develop professional services in the community, such as a mother who opened up programs offering intensive outpatient and MATs to individuals with SUDs, and services to their families (Daley 2017b). There are many instances of family members organizing MSPs in their communities.

\section{Helping Children in the Family}

Professional treatment and/or participation in MSPs may also help parents engage their children in discussions of the problem to help them better understand the SUD (Daley and Douaihy 2010; Moe 2007). Some children may attend treatment sessions and MSPs depending on whether these services are available to them. Children benefit from sharing their experiences and feelings, having their feelings validated, and learning new coping strategies to manage their reactions to a parent's SUD. In some instances, a child may need professional help for a mental health, substance use, behavior, or academic problem.

\section{Policy Implications}

There is a need for everyone concerned about or involved with OUDs and other SUDs to understand that these disorders are not limited to affected individuals. Clearly, these problems often have profound and long-lasting adverse effects on families and their members, including children. This includes medical, social service, criminal justice, legal, and religious professionals who often encounter individuals or families. Legislators and policymakers who develop legislation and fund treatment for SUDs need to include the family in their efforts to address SUD in the community. Failure to do so will only add to the family burden and convey the message that addiction is an individual and not a family problem. 
Families and children can be helped indirectly if the member with the SUD receives help, engages in a recovery program, puts his or her life back together, and functions as a responsible member of the family and community. When possible, it is beneficial for families to be involved in educational, support, and treatment services to help them understand SUDs, what they can and cannot do to help their loved one and their family, and how they can address any of the consequences of the SUD on their family or its members. Treatment programs that exclude families do them a disservice.

Table 1 summarizes ideas adapted from a recent article that a colleague and one of the authors (DD) wrote about the impact of the opioid epidemic on families and children, as well as additional ideas about policies to help

\section{Table 1. Summary Table of Policy Implications}

\section{Support for the extended family. The concerns, problems, and needs of family} members affected by SUDs need to be heard, understood, and accepted by anyone involved in planning, providing, or funding services for SUDs. This should include not just family members who may live with the person with the SUD, but others who are affected. For example, grandparents are often affected when their adult son or daughter with one or more children struggles with an OUD or other SUD and is unable to establish or sustain recovery. Some grandparents become primary caretakers of young children, which can create an emotional and financial burden. While grandparents care about their grandchildren, most did not plan to be surrogate parents to their grandchildren.

\section{The importance of a family-based approach. Considering the family perspective holds} true whether these services are offered in licensed addiction programs, medical settings such as emergency rooms, medical or psychiatric hospitals, primary care and other specialty practices, or prisons and jails. Even if a professional never sees a family due to the nature of services offered (e.g., in a prison or jail), services can address the impact of SUDs on the family and what may help them so that the person with the SUD has a better understanding of the family nature of this disorder as well as community services for families.

3. Family education and support. Family education and support programs should be integrated in organizations or programs offering SUD treatment and recovery support services. Family education can include information on: the causes, effects, and symptoms of SUDs; the neurobiology of addiction (promoting it as a brain disease); treatment and recovery options including medications for opioid, alcohol, or nicotine addiction; the prospects of long-term recovery from SUDs; causes of relapse and strategies to reduce relapse risk; the diversity of pathways of recovery; the role of social support; types and functions of mutual support programs for SUDs and families; the effects of opioid and other SUDs on the family and family members including children; and the commonly experienced stages of family recovery. Families need to understand that there are no short-term solutions to SUDs, and that long-term involvement in treatment and/or recovery increases the chances of sustaining changes over time. We have heard family members express relief when their loved one entered a rehabilitation program without realizing that this is only the beginning of recovery and must be followed with ongoing care. 


\section{Table 1 (continued)}

4. Counseling services. When possible, counseling services should be offered to families and individual members, including children and siblings, to help them deal with the impact of the SUD on family life and on the health and functioning of individual members. Many addiction programs offer family education but not counseling services. Few offer services to children, perhaps assuming that parents involved in treatment will help their children deal with the SUD.

5. Education. Education about and linkages to peer-based family mutual support programs should be provided. Some family programs use volunteers in recovery to help new members engage in MSPs.

6. Volunteers. Family members in recovery who have made healthy adjustments to the SUD and have learned to cope with their own reactions can serve as volunteers when possible to help families new to the process. They may be part of, or independent of, MSPs or professional treatment programs.

7. Grief services. Too many families lose a loved one to death from an overdose; medical complications of an alcohol, drug, or tobacco addiction; accidents; suicides; or homicides. Services should be offered to help families share their stories and deal with these losses. Grief groups, if available, can serve as an excellent resource to these family members (Daley 2017a).

8. Family-oriented care. Family-oriented care within treatment programs spans the functions of assessment; treatment and recovery planning; service delivery; and posttreatment monitoring (such as recovery checkups), support, and if and when needed, early re-intervention if a relapse occurs.

Source: White, William, and Dennis Daley. 2016. "Calling Attention to Opioid Affected Families and Children." William L. White Blog, July 13. http://www.williamwhitepapers.com/blog/2016/07/ calling-attention-to-opioid-affected-families-and-children-william-white-and-dr-dennis-c-daley.html. Accessed March 3, 2017.

families and children (White and Daley 2016). These ideas are relevant to other SUDs, as opioid problems are just one type of substance problem that affects our communities.

\section{Help for Families Through the Legal and Criminal Justice Systems}

The health of criminal justice populations can be improved through improved integration of services, and making changes in the system to coordinate and/ or provide evidence-based services for SUDs and mental health disorders (Freudenberg and Heller 2016). Other ways for legal and criminal justice systems to help individuals and families include the following.

\section{Legal Means}

Use legal means to pressure the member with the SUD to engage and participate in treatment. Encouraging accountability to the legal system by 
monitoring the participation and progress of the person with the SUD can provide extrinsic motivation until the person internalizes the desire to change.

\section{Educational or Clinical Treatment in Jails}

When feasible, offer SUD educational or clinical treatment services in jails or prisons so that individuals with SUDs become more knowledgeable about SUDs, more involved in treatment and recovery, and more likely to develop a desire to continue with the services upon release from incarceration.

\section{Medication-Assisted Treatment}

For those with OUDs, facilitate the initiation of MAT prior to release so that the person is more stable when returning to the community (Lee et al. 2017). The person can also be educated about overdose potential and given naloxone or information about where to get this drug, since those who use opioids soon after release are at risk for overdose due to changes in their tolerance levels and differences in the potency of street drugs like heroin.

\section{Education About Risk Factors}

Educate offenders and families about the risk factors for reoffending, such as: using alcohol or drugs; breaking the law or performing antisocial acts; showing negative patterns of behavior based on personality; spending time with people who are antisocial or have no respect for the law; poor relationships and connections with others; trouble at work or school; or a lack of healthy leisure or recreational activities.

\section{On-Site Meetings}

When feasible, facilitate on-site meetings of mutual support programs such as AA, NA, or SMART Recovery. These programs help connect people with others in recovery who can provide support during or after incarceration. Many people in recovery have personal experience with the criminal justice system and can serve as mentors or positive role models for those with SUDs who are incarcerated.

\section{Resources for Families}

There are resources in the State of Pennsylvania and across the United States that provide information and support for those affected by SUDs, but it is clear that more resources and easier access to help are needed for families affected by a loved one's addiction. Please refer to the Appendix to this article for detailed information about these resources. 


\section{Concluding Remarks}

The opioid epidemic and other substance problems affect nearly everyone in our society, including families who experience adverse effects when a loved one has an SUD. Any substance problem can have an impact on a person's physical, mental, emotional, and financial health and create a severe burden for the family.

This major health, social, and safety problem cannot be effectively addressed without considering the impact of SUDs on families and members, including children, and including them in treatment and recovery. While addiction is promoted as a "family disease," in reality many family members are not offered the opportunity to engage in treatment for their own health. Promoting awareness of this often forgotten population and finding longterm solutions to help support vulnerable families need to occur on all levels: individual, societal, and political. Families and children need and deserve the utmost consideration in policies that affect how we support them. While there are family-oriented treatments and mutual support programs available to help families, we all need to do a better job educating families, connecting them with these resources, and addressing their concerns and problems. Any expansion of clinical services for opioid and other addictions should include services and help for families and members, including children.

\section{APPENDIX}

Resources for Families

1. Al-Anon (al-anon.org). This is a mutual support program for friends and families of individuals with alcohol problems.

2. Alateen (al-anon.org/for-members/group-resources/alateen/). This is a fellowship of young Al-Anon members, usually teenagers, whose lives have been affected by someone else's drinking. Like Al-Anon, Alateen provides group meetings where members share experiences and learn the principles of the Al-Anon program.

3. Bridge to Hope (bridge2hope.org/). This is a family support program in the Pittsburgh area that offers education and help for families and concerned others affected by a loved one's addiction.

4. Community Reinforcement Approach and Family Training (CRAFT) (www.robertjmeyersphd.com/craft.html). This is an approach to help families and significant others deal with a substance use problem in the family. It provides guidance on how to engage the member with the substance problem in treatment. It 
also helps the family deal with their own reactions to a loved one and engage in their own recovery.

5. Faces and Voices of Recovery (facesandvoicesofrecovery.org). This is an advocacy organization that provides information and support for families and those with a substance use disorder.

6. Facing Addiction (www.facingaddiction.org). This is an advocacy organization dedicated to finding solutions to the addiction crisis. They aim to build a national constituency, increase access to treatment, translate scientific innovation into services, advocate for governments to implement evidence-based policies, and share the proof of long-term recovery.

7. Family Resource Center (www.familyresourcectr.org/category/ community/). This website has various resources for families to understand and address a child's substance use. The resources can be filtered by the intended user, for example, parents of young adolescents, older teens, adult children, or teachers/community support personnel.

8. Nar-Anon (www.nar-anon.org/). This is a mutual support program for families affected by any type of drug problem.

9. National Association of Children of Alcoholics (nacoa.org). This is an advocacy group that aims to eliminate the adverse impact of alcohol and drug use on children and families. Their goals are to raise public awareness; provide leadership in public policy at the national, state, and local levels; inform and educate the community; disseminate information; and advocate for accessible programs and services.

10. National Institute on Drug Abuse (NIDA) (www.drugabuse.gov/ patients-families). NIDA provides information on many topics of interest for families, including information about drugs, treatment programs, and current research initiatives.

11. Partnership for Drug-Free Kids (drugfree.org). This is a nonprofit organization that aims to help families struggling with their son or daughter's substance use. They provide information, support, and guidance to families, in addition to advocating for greater understanding and more effective programs to treat addiction. They offer a helpline that helps families connect with experts.

12. Sage's Army (www.sagesarmy.com). This is a nonprofit drug awareness and prevention organization in Westmoreland County (western PA) that aims to offer support, guidance, and encouragement to others who have also been affected by addiction. They offer 
monthly community meetings, presentations in the community, and information about resources available for those suffering from addiction.

\section{Pennsylvania State Resources}

These resources can help the family locate licensed alcohol and drug treatment programs in any county in the state. Some include educational resources on topics related to opioid use disorders or other SUDs.

1. PA Department of Drug and Alcohol Programs (www.ddap.pa .gov/). This site provides information about SUDs, overdoses, naloxone, clinical guidelines to determine level of care needed, and treatment resources throughout the state (see "Find Treatment Services").

2. PA Get Help Now (apps.ddap.pa.gov/gethelpnow/Index.aspx) 1-800-662-4357. This website and helpline provide information about local resources for substance use disorders. Go to "Care Provider Search" and enter the county name or zip code of the area in which you are looking for treatment programs. This helpline can also direct you to funding alternatives for the uninsured who may not be eligible for Medicaid.

\section{Federal Government Resources}

These websites provide a rich array of free educational, clinical, and research resources on substance use and SUDs, including OUDs. All include access to e-files with this information, including screening tools and treatment manuals and protocols for professionals.

\section{National Institute on Alcohol Abuse and Alcoholism (NIAAA)} (www.niaaa.nih.gov/). This site provides information on alcohol problems, treatment, and research. It includes information for professionals, individuals with alcohol problems, and families.

2. National Institute on Drug Abuse (NIDA) (www.drugabuse.gov/). This site provides information on substances, substance use disorders, opioid overdoses, treatment, and research. There are specific links with tools for brief screening of a drug problem by professionals to assess opioid risk or opioid withdrawal symptoms (e.g., 
NIDA Quick Screen; DAST-10; Clinical Opioid Withdrawal Scale; and Opioid Risk Tool).

\section{Substance Abuse and Mental Health Services Administration}

(SAMHSA) (www.samhsa.gov/). This site provides treatment and recovery resources and information on evidence-based practices for SUDs.

See samhsa.gov/medication-assisted-treatment for training materials and provider resources on the use of medication for opioid addiction, and waivers for physicians, nurse practitioners, and physician assistants.

See www.samhsa.gov/nrepp to access the National Registry of EvidenceBased Programs and Practices (NREPP).

\section{REFERENCES}

Ackerman, Robert. 1987. Children of Alcoholics: A Guide for Parents, Educators, and Therapists. 2nd ed. New York: Simon and Schuster.

- 2002. Perfect Daughters: Adult Daughters of Alcoholics. Revised Ed. Deerfield Beach, FL: Health Communications.

Al-Anon Family Groups. 1981. Alateen: Hope for Children of Alcoholics. New York: AlAnon Family Group Headquarters.

—. 1984. Al-Anon Faces Alcoholism. 2nd ed. New York: Al-Anon Family Group Headquarters.

Alexander, G. Caleb, ed. 2015. The Prescription Opioid Epidemic: An Evidence-Based Approach. Baltimore: Johns Hopkins Bloomberg School of Public Health.

Andreas-Burdzovic, Jasmina, and Timothy O’Farrell. 2007. "Longitudinal Associations Between Fathers' Heavy Drinking Patterns and Children's Psychosocial Adjustment.” Journal of Abnormal Child Psychology 35 (February): 1-16.

Association for Community Affiliated Plans (ACAP). 2017. Responding to the Prescription Opioid Crisis. Washington, DC: ACAP.

Bagley, Sarah, Leah Forman, Sarah Ruiz, Kevin Cranston, and Alexander Walley. 2017. "Expanding Access to Naloxone for Family Members: The Massachusetts Experience." Drug and Alcohol Review. Early publication April 20.

Barnard, Marina, and Neil McKeganey. 2004. "The Impact of Parental Problem Drug Use on Children: What Is the Problem and What Can Be Done to Help?" Addiction 99 (May): 552-559.

Baser, Onur, Mady Chalk, David Fiellin, and David Gastfriend. 2011. "Cost and Utilization Outcomes of Opioid-dependence Treatments. American Journal of Managed Care 17 (June): S235-S248.

Baser, Onur, Mady Chalk, Richard Rawson, and David Gastfriend. 2011. "Alcohol Dependence Treatments: Comprehensive Healthcare Costs, Utilization Outcomes, and Pharmacotherapy Persistence." American Journal of Managed Care 17 (June): S222S234.

Berry, James, Carl Sullivan, Julie Kmiec, and Antoine Douaihy. 2013. "Substances of Abuse and Their Clinical Implications." In Substance Use Disorders, eds. Antoine Douaihy and Dennis Daley. New York: Oxford University Press, 93-136. 
Centers for Disease Control and Prevention (CDC). 2017. Tobacco-Related Mortality. Available at www.cdc.gov/tobacco/data_statistics/fact_sheets/fast_facts/. Accessed January 9, 2017.

Cicero, Theodore, Matthew Ellis, and Hilary Suratt. 2015. "The Changing Face of Heroin Use in the United States: A Retrospective Analysis of the Past 50 Years." JAMA Psychiatry 71 (July): 821-826.

Committee on Obstetric Practice. 2017. "Committee Opinion No. 771: Opioid Use and Opioid Use Disorder in Pregnancy.” Obstetric Gynecology 130 (August): e81-e94.

Compton, Wilson. 2015. Cannabis: Linking Epidemiology and Neuroscience. Available at www.slideshare.net/the-shifting-marijuana-legal-environment. Accessed February $1,2017$.

Conners, Nicola, Robert H. Bradley, Leanne Whiteside Mansell, Jeffery Y. Liu, Tracy J. Roberts, Ken Burgdorf, and James M. Herrell. 2004. "Children of Mothers with Serious Substance Abuse Problems: An Accumulation of Risks." The American Journal of Drug and Alcohol Abuse 30 (November): 85-100.

Copello, Alex, Richard Velleman, and Lorna Templeton. 2005. "Family Interventions in the Treatment of Alcohol and Drug Problems." Drug and Alcohol Review 24 (July): 369-385.

Daley, Dennis. 2017a. "Grief Has No Expiration Date. Part 1: Losing a Loved One to Addiction." Counselor 18 (October): 19-22.

—. 2017b. "Grief Has No Expiration Date. Part 2: Coping with the Loss of a Loved One to Addiction." Counselor 18 (October): 24-26.

Daley, Dennis, and Antoine Douaihy. 2010. A Family Guide to Addiction and Recovery. Murrysville, PA: Daley Publications.

- 2015. Relapse Prevention Counseling: Clinical Strategies to Guide Addiction Recovery and Reduce. Eau Claire, WI: PESI Publishing \& Media.

—. 2017. "Drug Use Disorders." In The SAGE Encyclopedia of Abnormal and Clinical Psychology, ed. Amy Wenzel. Thousand Oaks, CA: SAGE, 1196-1200.

Daley, Dennis, and Judy Miller. 2001. Addiction in Your Family: Helping Yourself and Your Loved Ones. Holmes Beach, FL: Learning Publications.

Daley, Dennis, and Howard Moss. 2002. Dual Disorders: Counseling Clients with Chemical Dependency and Mental Illness. 3rd ed. Center City, MN: Hazelden.

Daley, Dennis, and Ralph Tartar. 2017. "Children of Parents with Substance Use Disorder." In The SAGE Encyclopedia of Abnormal and Clinical Psychology, ed. Amy Wenzel. Thousand Oaks, CA: SAGE, 643-644.

Daley, Dennis, and Michael Thase. 2004. Dual Disorders Recovery Counseling: Integrated Treatment for Substance Use and Psychiatric Disorders. 3rd ed. Independence, MO: Independence Press.

Dart, Richard, Hilary L. Surratt, Theodore J. Cicero, Mark W. Parrino, Geoff Severtson, Becki Bucher-Bartelson, and Jody L. Green. 2015. "Trends in Opioid Analgesic Abuse and Mortality in the United States." New England Journal of Medicine 372 (January): 241-248.

Denniston, Robert. 2017. "What's Missing in the Surgeon General's Report on Alcohol, Drugs, and Health?” Counselor 18 (June): 10-11.

Douaihy, Antoine, and Dennis Daley. 2013. Substance Use Disorders: Pittsburgh Pocket Psychiatry. New York: Oxford University Press.

- 2017. "Alcohol Use Disorder." In The SAGE Encyclopedia of Abnormal and Clinical Psychology, ed. Amy Wenzel. Thousand Oaks, CA: SAGE, 96-99. 
Frank, Richard, and Harold Pollack. 2017. "Addressing the Fentanyl Threat to Public Health.” New England Journal of Medicine 376 (February): 605-607.

Freudenberg, Nicholas, and Daliah Heller. 2016. "A Review of Opportunities to Improve the Health of People Involved in the Criminal Justice System in the United States." Annual Review of Public Health 37 (January): 313-333.

Friedmann, Peter. 2013. "Alcohol Use in Adults." New England Journal of Medicine 368 (January): 365-373.

Gaines, W. S. 2011. Blood on a Pew. Mustang, OK: Tate Publishing.

Grant, Bridget, S. Patricia Chou, Tulshi D. Saha, Roger P. Pickering, Bradley T. Kerridge, W. June Ruan, Boji Huang, Jeesun Jung, Haitao Zhang, Amy Fan, and Deborah S. Hasin. 2017. "Prevalence of 12-month Alcohol Use, High-risk Drinking, and DSM-IV Alcohol Use Disorder in the United States, 2001-2002 to 2012-2013.” JAMA Psychiatry 74 (September): 911-923.

Jansson, Lauren, and Martha Velez. 2010. "Neonatal Abstinence Syndrome.” Current Opinion in Pediatrics 24 (April): 252-258.

Jones, Hendrée, Karol Kaltenbach, Sarah H. Heil, Susan M. Stine, Mara G. Coyle, Amelia M. Arria, Kevin E. O'Grady, Peter Selby, Peter R. Martin, and Gabriele Fischer. 2010. "Neonatal Abstinence Syndrome After Methadone or Buprenorphine Exposure." New England Journal of Medicine 363 (December): 2320-2332.

Kaufman, Edward, and Marianne Yoshioka. 2004. Substance Abuse and Family Therapy: A Treatment Improvement Protocol 39. Rockville, MD: Substance Abuse and Mental Health Services Administration.

Kelly, Thomas, and Dennis Daley. 2013. "Integrated Treatment of Substance Use and Psychiatric Disorders." Social Work in Public Health 28 (May-July): 388-406.

Kendler, Kenneth, Henrik Ohlsson, Jan Sundquist, and Kristina Sundquist. 2016. "Alcohol Use Disorder and Mortality Across the Lifespan: A Longitudinal Cohort and Corelative Analysis." Journal of the American Medical Association 73 (June): 575-581.

Kessler, Ronald, Rosa M. Crum, Lynn A. Warner, Christopher B. Nelson, John Schulenberg, and James C. Anthony. 1997. "Lifetime Co-occurring of DSM-III-R Alcohol Abuse and Dependence with Other Psychiatric Disorders in the National Comorbidity Survey." Archives of General Psychiatry 54 (April): 313-321.

Kirisci, Levent, Michael Vanyukov, and Ralph Tarter. 2005. "Detection of Youth at High Risk for Substance Use Disorders: A Longitudinal Study." Psychology of Addictive Behaviors 19 (September): 243-252.

Klostermann, Keith, and Timothy O’Farrell. 2013. “Treating Substance Abuse: Partner and Family Approaches." Social Work in Public Health 28 (May-July): 234-247.

Kmiec, Julie, Jack Cornelius, and Antoine Douaihy. 2013. "Pharmacotherapy of Substance Use Disorders.” In Substance Use Disorders: Pittsburgh Pocket Psychiatry, eds. Antoine Douaihy and Dennis Daley. New York: Oxford University Press, 169-212.

Koh, Howard. 2015. "Community Approaches to the Opioid Crisis." Journal of the American Medical Association 314 (October): 1437-1438.

Kraft, Walter, Susan C. Adeniyi-Jones, Inna Chervoneva, Jay S. Greenspan, Diana Abatemarco, Karol Kaltenbach, and Michelle E. Ehrlich. 2017. "Buprenorphine for the Treatment of the Neonatal Abstinence Syndrome." New England Journal of Medicine 376 (June): 2341-2348.

Landau, Judith, James Garrett, Robert R. Shea, M. Duncan Stanton, David BrinkmanSull, and Gloria Baciewicz. 2000. "Strength in Numbers: The ARISE Method for Mobilizing Family and Network to Engage Substance Abusers in Treatment." The American Journal of Drug and Alcohol Abuse 26 (July): 379-398. 
Lander, Laura, Janie Howsare, and Marilyn Byrne. 2013. "The Impact of Substance Use Disorders on Families and Children." Social Work in Public Health 28 (July): 194-203.

Lee, Joshua, Peter Friedman, Timothy W. Kinlock, Edward V. Nunes, Tamara Y. Boney, Randall A. Hoskinson, Jr., Donna Wilson, Ryan McDonald, John Rotrosen, Marc N. Gourevitch, Michael Gordon, Marc Fishman, Donna T. Chen, Richard J. Bonnie, James W. Cornish, Sean M. Murphy, and Charles P. O’Brien. 2017. "Extended-Release Naltrexone to Prevent Opioid Relapse in Criminal Justice Offenders.” New England Journal of Medicine 374 (March): 1232-1242.

Liebschutz, Jane, Denise Crooks, and Debra Herman. 2014. "Buprenorphine Treatment for Hospitalized, Opioid-Dependent Patients: A Randomized Clinical Trial.” JAMA Internal Medicine 174 (August): 1369-1376.

Liepman, Michael, Kathleen A. Gross, Maritza M. Lagos, Theodore V. Parran, and Kathleen J. Farkas. 2014. "Family Involvement in Addiction, Treatment and Recovery." In The ASAM Principles of Addiction Medicine, 5th ed., eds. Richard K. Ries, David A. Fiellin, Shannon C. Miller, and Richard Saitz. New York: Wolters Kluwer, 958-974.

Marlatt, Alan, and Dennis Donovan. 2005. Relapse Prevention. 2nd ed. New York: Guilford.

McCarty, Dennis, Nancy A. Perrin, Carla A. Green, Michael R. Polen, Michael C. Leo, and Frances Lynch. 2010. "Methadone Maintenance and the Cost and Utilization of Health Care Among Individuals Dependent on Opioids in a Commercial Health Plan.” Drug Alcohol Dependence 111 (October): 235-240.

McMahon, Thomas J. 2013. "Substance Abusing Fathers: A Development Perspective." In Parenting and Substance Abuse: Developmental Approaches to Intervention, eds. Nancy Suchman, Marjukka Pajulo, and Linda Mayes. New York: Oxford University Press, 156-184.

Meyers, Robert, and Brenda Wolfe. 2004. Getting Your Loved One Sober: Alternatives to Nagging, Pleading and Threatening. Center City, MN: Hazelden.

Minear, Susan, and Barry Zuckerman. 2013. "Interventions for Children of SubstanceUsing Parents.” In Parenting and Substance Abuse: Developmental Approaches to Intervention, eds. Nancy Suchman, Marjukka Pajulo, and Linda Mayes. New York: Oxford University Press, 235-257.

Moe, Jerry. 2007. Understanding Addiction and Recovery Through a Child's Eyes: Hope, Help, and Healing for Families. Deerfield Beach, FL: Health Communications.

Moss, Howard, Michael Vanyukov, Partha P. Majumder, Levent Kirisci, and Ralph E. Tarter. 1995. "Prepubertal Sons of Substance Abusers: Influences of Parental and Familial Substance Abuse on Behavioral Disposition, IQ and School Achievement." Addictive Behaviors 20 (May-June): 1-14.

Myrick, Hugh, Henry R. Kranzler, Domenic A. Ciraulo, Andrew J. Saxon, and Jerome H. Jafee. 2014. "Medications for Use in Alcohol Rehabilitation." In The ASAM Principles of Addiction Medicine, 5th ed., eds. Richard K. Ries, David A. Fiellin, Shannon C. Miller, and Richard Saitz. New York: Wolters Kluwer, 713-726.

National Center on Addiction and Substance Abuse at Columbia University (CASA). 2012. Addiction Medicine: Closing the Gap between Science and Practice. New York: CASA.

National Institute on Alcohol Abuse and Alcoholism (NIAAA). 2017. Fetal Alcohol Exposure. Available at http://www.niaaa.nih.gov/alcohol-health/fetal-alcohol-exposure. Accessed August 19, 2017.

National Institute on Drug Abuse (NIDA). 2012. Principles of Drug Addiction Treatment: A Research-Based Guide. 3rd ed. Bethesda, MD: U.S. Department of Health and Human Services. 
Nunes, Edward, Myrna M. Weissman, Rise Goldstein, Gail McAvay, Carla Beckford, Angela Seracini, Helena Verdeli, and Priya Wickramaratne. 2000. "Psychiatric Disorders and Impairment in the Children of Opiate Addicts: Prevalence and Distribution by Ethnicity." American Journal on Addictions 9 (Summer): 232-241.

Orford, Jim, Richard Velleman, Guillermina Natera, Lorna Templeton, and Alex Copello. 2013. "Addiction in the Family is a Major But Neglected Contributor to the Global Burden of Adult Ill-health.” Elsevier Social Science \& Medicine 78 (February): 70-77.

Regier, Darrel. 1990. "Comorbidity of Mental Disorders with Alcohol and Other Drug Abuse: Results from the Epidemiologic Catchment Area Study." Journal of the American Medical Association 264 (November): 2511-2518.

Salo, Saaro, and Marjo Flykt. 2013. "The Impact of Parental Addiction on Child Development." In Parenting and Substance Abuse: Developmental Approaches to Intervention, eds. Nancy Suchman, Marjukka Pajulo, and Linda Mayes. New York: Oxford University Press, 195-210.

Schuckit, Marc. 2016. “Treatment of Opioid-Use Disorders.” New England Journal of Medicine 375 (July): 357-368.

Schwartzmier, Michelle. 2017. "My Daughter Died from an Overdose. I'm Sharing Her Story to Help Others.” Partnership for Drug-Free Kids, August 22. Available at https:// drugfree.org/parent-blog/my-daughter-died-from-an-overdose-im-sharing-herstory-to-help-others/. Accessed August 22, 2017.

Smith, Erin, and Dennis Daley. 2017. "Substance Use Disorders and the Family." In The SAGE Encyclopedia of Abnormal and Clinical Psychology, ed. Amy Wenzel. Thousand Oaks, CA: SAGE.

Solis, Jessica, Julia M. Shadur, Alison R. Burns, and Andrea M. Hussong. 2012. "Understanding the Diverse Needs of Children Whose Parents Abuse Substances." Current Drug Abuse Reviews 5 (June): 135-137.

Soyka, Michael. 2017. "Treatment of Benzodiazepine Dependence." New England Journal of Medicine 376 (March): 1147-1157.

Stanton, M. Duncan, and William Shadish. 1997. "Outcome, Attrition, and Familycouples Treatments for Drug Abuse: A Meta-analysis and Review of the Controlled, Comparative Studies." Psychological Bulletin 122 (September): 170-191.

Stine, Susan, and Thomas Kosten. 2014. "Pharmacologic Interventions for Opioid Dependence." In The ASAM Principles of Addiction Medicine, 5th ed., eds. Richard K. Ries, David A. Fiellin, Shannon C. Miller, and Richard Saitz. New York: Wolters Kluwer, 735-758.

Substance Abuse and Mental Health Services Administration (SAMHSA). 2009. "Alcohol Behavioral Couple Therapy." National Registry of Evidence-based Programs and Practices. Rockville, MD: Substance Abuse and Mental Health Services Administration.

- 2015a. 2014 National Survey on Drug Use and Health. Rockville, MD: SAMHSA. .2015b. Medication for the Treatment of Alcohol Use Disorders: A Brief Guide. Rockville, MD: HSS Publication No. (SMA) 15-4907.

- 2016. 2015 National Survey on Drug Use and Health. Rockville, MD: SAMHSA.

Suchman, Nancy, Marjukka Pajulo, and Linda Mayes. 2013. Parenting and Substance Abuse: Developmental Approaches to Intervention. New York: Oxford University Press.

Szapocznik, José, Olga Hervis, and Seth Schwartz. 2003. Brief Strategic Family Therapy for Adolescent Drug Abuse. Rockville, MD: U.S. Department of Health and Human Services. 
Szapocznik, José, Monica Zarate, Jonathan Duff, and Joan Muir. 2013. "Brief Strategic Family Therapy: Engaging Drug Using/Problem Behavior Adolescents and Their Families in Treatment." Social Work in Public Health 28 (May): 206-223.

Tarter, Ralph, Timothy Blackson, Janet Brigham, Howard Moss, and Gian Vittorio Caprara. 1995. "The Association Between Childhood Irritability and Liability to Substance Use in Early Adolescence: A Two-year Follow-up Study of Boys at Risk for Substance Abuse." Drug and Alcohol Dependence 39 (October): 253-261.

Tarter, Ralph, Levent Kirisci, Maureen Reynolds, and Ada Mezzich. 2004. "Neurobehavior Disinhibition in Childhood Predicts Suicide Potential and Substance Use Disorder by Young Adulthood." Elsevier Drug and Alcohol Dependence 76S (December): S45-S52.

Templeton, Lorna, Richard Velleman, and Claire Russell. 2010. "Psychological Interventions with Families of Alcohol Misusers: A Systematic Review." Addiction Research \& Theory 18 (October): 616-648.

Van Gundy, Karen. 2006. Substance Abuse in Rural and Small Town America. Durham, $\mathrm{NH}$ : The Carsey Institute, University of New Hampshire.

Viteri, Oscar, Eleazar E. Soto, Ray O. Bahado-Singh, Carl W. Christensen, Suneet P. Chauhan, and Baha M. Sibai. 2015. "Fetal Anomalies and Long-term Effects Associated with Substance Abuse in Pregnancy: A Literature Review." American Journal of Perinatology 32 (April): 405-416.

Volkow, Nora, George Koob, and A. Thomas McLellan. 2016. "Neurobiologic Advances from the Brain Disease Model of Addiction." New England Journal of Medicine 374 (January): 363-371.

Volkow, Nora, Ruben Baler, Wilson Compton, and Susan Weiss. 2014. "Adverse Health Effects of Marijuana Use.” New England Journal of Medicine 370 (June): 2219-2227.

Volkow, Nora, and Joanna Fowler. 2000. "Addiction, a Disease of Compulsion and Drive: Involvement of the Orbitofrontal Cortex." Cerebral Cortex 10 (March): 318-325.

Wallace, Kelly. 2014. "Being an Addict's Mom: It's Just a Very, Very Sad Place." CNN, August 26. Available at http://www.cnn.com/2014/08/26/living/addiction-parents/ index.html. Accessed August 26, 2014.

Ward, Joan, and Dennis Daley. 2014. "A Parent's Journey to Recovery." Counselor Connection 8 (December): 1-4.

Weisner, Connie. 2010. “Cost Studies at Northern California Kaiser Permanente.” Presented to County Alcohol and Drug Program Administrators, Sacramento, CA.

Weiss, Roger, Jennifer Sharpe Potter, Margaret L. Griffin, Scott E. Provost, Garret D. Fitzmaurice, Katherine A. McDermott, Emily N. Srisarajivakul, Dorian R. Dodd, Jessica A. Dreifuss, R. Kathryn McHugh, and Kathleen M. Carroll. 2015. "Longterm Outcomes from the National Drug Abuse Treatment Clinical Trials Network Prescription Opioid Addiction Treatment Study." Drug and Alcohol Dependence 150 (May): 112-119.

White, William L. 2014. "Anticipatory Grief and Family Recovery." William L. White Blog, January 3. Available at http://www.williamwhitepapers.com/blog/2014/01/ anticipatory-grief-and-family-recovery.html. Accessed March 3, 2017.

White, William, and Bob Savage. 2005. "All in the Family: Alcohol and Other Drug Problems, Recovery, Advocacy." Alcohol Treatment Quarterly 23: 3-37.

White, William L., and Dennis Daley. 2016. "Calling Attention to Opioid-Affected Families and Children." William L. White Blog, July 13. Available at: http://www .williamwhitepapers.com/blog/2016/07/calling-attention-to-opioid-affected -families-and-children-william-white-and-dr-dennis-c-daley.html. Accessed March 3, 2017. 
Young, John, Andrea H. Kline-Simon, Donald J. Mordecai, and Constance Weisner. 2015. "Prevalence of Behavioral Health Disorders and Associated Chronic Disease Burden in a Commercially Insured Health System: Findings of a Case-control Study." Elsevier General Hospital Psychiatry 37 (March-April): 101-108.

Yule, Amy, Timothy Wilens, and Paula Rauch. 2017. "The Opioid Epidemic: What Is a Child Psychiatrist to Do?" Journal of the American Academy of Child \& Adolescent Psychiatry 56 (July): 541-543.

Dennis C. Daley is senior clinical director of substance use services at UPMC Health Plan, and professor of psychiatry in the Department of Psychiatry at the University of Pittsburgh School of Medicine. He previously served as chief of addiction medicine services at Western Psychiatric Institute and Clinic. Dr. Daley has over 30 years of experience in clinical care, research, and teaching. He has over 350 publications, including treatment manuals, books and chapters, papers, and recovery guides for individuals with substance use disorders, and families. Several of his publications have been translated to foreign languages.

Erin Smith is a consulting psychiatrist in Vancouver, Canada. She works at BC Children's Hospital with youth who have co-occurring disorders and at BC Women's Hospital with women who are pregnant and postpartum. She completed her residency and an addictions fellowship at UPMC Western Psychiatric Institute and Clinic. Her professional interests include medical student and resident education, and motivational interviewing.

Daniel Balogh is a project manager for the Behavioral Integration Team at UPMC Health Plan in Pittsburgh, Pennsylvania. He is involved with multiple initiatives addressing opioid and other substance use disorders (SUDs). He has coauthored several publications on SUDs.

Jodi Toscolani is a project manager at the UPMC Health Plan Substance Use Services in the Behavioral Health Integration Division. She has an extensive background as a clinician, supervisor, program director, and educator in behavioral health services. Jodi is involved in multiple projects addressing substance use problems in our community, including the opioid epidemic. 